\title{
Surface modeling of soil antibiotics
}

\author{
Wen-jiao Shi ${ }^{\text {a }}$, Tian-xiang Yue ${ }^{\text {b,* }}$, Zheng-ping Du ${ }^{\mathrm{b}}$, Zong Wang ${ }^{\text {a,d }}$, Xue-wen Li $^{\mathrm{c}, *}$

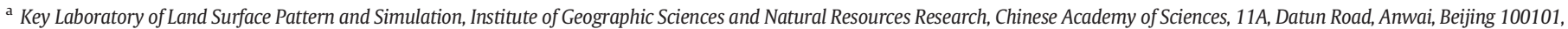 \\ China

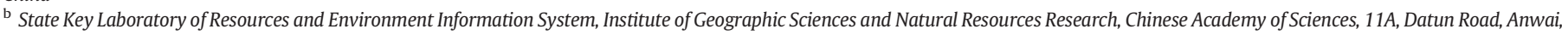 \\ Beijing 100101, China \\ c Department of Environment and Health, School of Public Health, Shandong University, Jinan 250012, China \\ d School of Earth Sciences and Resources, China University of Geosciences, Beijing 100083, China
}

\section{H I G H L I G H T S}

- An effective method - HASM, was developed for the interpolation of soil antibiotics.

- The accuracy of HASM is higher than the classical methods.

- HASM can make the map more consistent with the true spatial distributions.
G R A P H I C A L A B S T R A C T

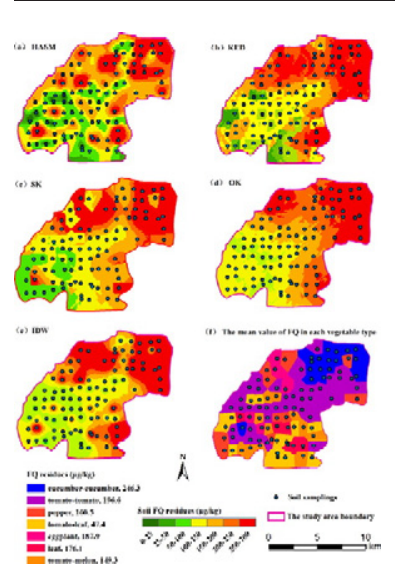

\section{A R T I C L E I N F O}

\section{Article history:}

Received 17 May 2015

Received in revised form 16 November 2015

Accepted 16 November 2015

Available online 22 November 2015

Editor: D. Barcelo

\section{Keywords:}

HASM

Soil antibiotics

Spatial distributions

Accuracy

\begin{abstract}
A B S T R A C T
Large numbers of livestock and poultry feces are continuously applied into soils in intensive vegetable cultivation areas, and then some veterinary antibiotics are persistent existed in soils and cause health risk. For the spatial heterogeneity of antibiotic residues, developing a suitable technique to interpolate soil antibiotic residues is still a challenge. In this study, we developed an effective interpolator, high accuracy surface modeling (HASM) combined vegetable types, to predict the spatial patterns of soil antibiotics, using 100 surface soil samples collected from an intensive vegetable cultivation area located in east of China, and the fluoroquinolones (FQs), including ciprofloxacin (CFX), enrofloxacin (EFX) and norfloxacin (NFX), were analyzed as the target antibiotics. The results show that vegetable type is an effective factor to be combined to improve the interpolator performance. HASM achieves less mean absolute errors (MAEs) and root mean square errors (RMSEs) for total FQs $(\mathrm{NFX}+\mathrm{CFX}+\mathrm{EFX})$, NFX, CFX and EFX than kriging with external drift (KED), stratified kriging (StK), ordinary kriging (OK) and inverse distance weighting (IDW). The MAE of HASM for FQs is $55.1 \mu \mathrm{g} / \mathrm{kg}$, and the MAEs of KED, StK, OK and IDW are $99.0 \mu \mathrm{g} / \mathrm{kg}, 102.8 \mu \mathrm{g} / \mathrm{kg}, 106.3 \mu \mathrm{g} / \mathrm{kg}$ and $108.7 \mu \mathrm{g} / \mathrm{kg}$, respectively. Further, RMSE simulated by HASM for FQs (CFX, EFX and NFX) are $106.2 \mu \mathrm{g} / \mathrm{kg}$ ( $88.6 \mu \mathrm{g} / \mathrm{kg}, 20.4 \mu \mathrm{g} / \mathrm{kg}$ and $39.2 \mu \mathrm{g} / \mathrm{kg}$ ), and less 30\% (27\%, $22 \%$ and $36 \%$ ), 33\% (27\%, $27 \%$ and $43 \%), 38 \%$ (34\%, $23 \%$ and $41 \%$ ) and $42 \%(32 \%, 35 \%$ and $51 \%$ ) than the ones by KED, StK, OK and IDW, respectively. HASM also provides better maps with more details and more consistent
\end{abstract}

\footnotetext{
* Corresponding authors.

E-mail addresses: yue@lreis.ac.cn (T. Yue), lxw@sdu.edu.cn (X. Li).
} 
maximum and minimum values of soil antibiotics compared with the measured data. The better performance can be concluded that HASM takes the vegetable type information as global approximate information, and takes local sampling data as its optimum control constraints.

(C) 2015 Elsevier B.V. All rights reserved.

\section{Introduction}

Because of the high nutrients requirement for vegetable growth and the restricted use of chemical fertilizers for organic vegetable productions, large numbers of livestock and poultry feces were applied into the soils of the intensive vegetable cultivation areas (Bound and Voulvoulis, 2004). Due to the widely use of antibiotics in treating disease, protecting animal health and improving the feeding efficiency of animals, some of the antibiotics via the manure application were imported in soils and been strongly adsorbed (Sarmah et al., 2006; Martínez-Carballo et al., 2007; Aust et al., 2008). Further, soil antibiotics can be transported to surface and ground water, and also can be taken up by plants (Kuchta and Cessna, 2009). The spatial distributions of soil antibiotics are complex, because they are all from the external sources, and have irregular transportation into water and the irregular absorption by different plants.

Given that soil application of animal manure as a supplement to organic fertilizer is a common practice in many countries, there is a growing international concern about the spatial distributions of antibiotic residues in the environment (Sarmah et al., 2006). Because an inaccurate spatial pattern estimation of the soil antibiotics will result in considerable bias in risk assessment, the spatial interpolation of soil antibiotics is vital to evaluate the potential risks to human and environment (Xie et al., 2012). Therefore, it is needed to develop an effective surface modeling method which is suitable to interpolate the spatial patterns of soil antibiotics.

Several interpolators, such as kriging (Stein et al., 1988; Stein and Corsten, 1991; Goovaerts, 1999; Webster and Oliver, 2001), inverse distance weighting (IDW) (Weber and Englund, 1992; Weber and Englund, 1994; Gotway et al., 1996; Panagopoulos et al., 2006) and splines (Webster and Oliver, 2001), can be used for the estimation of the spatial distributions of soil properties, and each one has its own limitations (Shi et al., 2009; Shi et al., 2011; Shi et al., 2012). Some previous studies about soil antibiotics showed that the distributions of antibiotic residues in soil follow a spatial stratification pattern in the east of China (Xie et al., 2012), so the spatial predictions of soil antibiotics are more difficult than other soil properties due to the diverse sources of soil antibiotics.

Soil sampling analysis can provide highly accurate data of soil antibiotics at sampling sites, but these sampling points are sparsely to satisfy the interpolation requirement. The previous studies show that the vegetable type is the major determinant of the spatial stratification of FQs in the soil, and different vegetables also have different accumulation ability. These findings provide us clues to interpolate soil antibiotics more accurately by combining the interpolators with vegetable types.

High accuracy surface modeling (HASM) is a spatial interpolation technique which can be combined with other information to achieve better interpolating accuracy (Yue, 2011). HASM combined with ancillary information, like land use, soil and parent rock types, has been successfully used in the surface modeling of soil properties (Shi et al., 2009; Shi et al., 2011; Shi et al., 2012). However, the previous studies have not considered the statistical characters in each categorical variable type and the spatial variation degree between the neighbor samplings, which should be involved in the interpolation of the soil antibiotics.

Fluoroquinolones (FQs), which are a group of widely prescribed antibiotics and have higher concentrations and longer residence time in soils (Zhao et al., 2010), are selected as the target substances in this study. The objectives of this study are i) to develop an interpolator of HASM combined with vegetable types which are suitable for the prediction of the spatial distributions of soil antibiotics, and (ii) to assess the performance of HASM in improving the soil antibiotic interpolation compared with kriging with External Drift (KED), stratified kriging (StK), and also ordinary kriging (OK) and inverse distance weighting (IDW).

\section{Materials and methods}

\subsection{The study area}

The study area is located in the east of China (Fig. 1a). It is a typical vegetable planting area, covering $160 \mathrm{~km}^{2}$. The main soil type is cinnamon soil, and followed by fluvo-aquic soil. According to the questionnaires investigated during the soil sampling collection, there are seven vegetable types in the study area, including cucumber-cucumber (growing cucumbers after cucumbers, $16 \%$ of the study area), tomatotomato (growing tomato after tomato, 39\%), pepper (11\%), tomatoleaf (growing tomato after leaf, 13\%), eggplant (6\%), leaf (5\%) and tomato-melon (growing tomato after melon, 10\%) (Fig. 1b). The main manure applied into the soils was chicken dung, and the application quantities in most areas were from $3 \mathrm{~kg} / \mathrm{m}^{2}$ to $9 \mathrm{~kg} / \mathrm{m}^{2}$ (Li et al., 2013). The elevation decreases from the south to the north with altitude ranging from $34 \mathrm{~m}$ to $5 \mathrm{~m}$, and the river distributions were shown in Fig. 1c. More information about the manure application categories and quantity, the spatial distributions of area of greenhouse and planting age were shown in the previous studies (Xie et al., 2012; Li et al., 2013; Li et al., 2014).

\subsection{Soil samples and analysis}

In order to compare the performance of different interpolation techniques, a total of 100 greenhouses were selected and in each of them the surface soil were collected following an S-shape in November 2010 (Fig. 1b). The interval of the soil samples in different greenhouses was approximately $1 \mathrm{~km}$. The sampling sites were designed to cover evenly the whole area and to include different vegetable planted types, different manure types, different planting years, etc. Three types of FQs, including ciprofloxacin (CFX), enrofloxacin (EFX), and norfloxacin (NFX) were analyzed using high-performance liquid chromatography and fluorescence detection (HPLC-FD). The molecular formulas of the three antibiotics were shown as Table 1 . The reagents and sample analysis methods were given in the former studies (Xie et al., 2012; Li et al., 2013; Li et al., 2014). The physical and chemical properties of soils in the study area can also be found in Li et al. (2013).

\subsection{HASM}

For the surface modeling of soil antibiotics, we propose a modified HASM combined with the information of vegetable type which is more suitable for the prediction of the spatial patterns of soil antibiotics. Because the detailed equations and the explanations of HASM have been published in the previous references (Shi et al., 2009; Shi et al., 2011; Shi et al., 2012), we only listed the main equations and the modified part in this study for HASM.

The matrix formulation of HASM master equations can be respectively expressed as (Yue, 2011; Yue et al., 2013, 2014, 2015),

$$
\left\{\begin{array}{l}
A F^{n+1}=c^{n} \\
B F^{n+1}=d^{n}
\end{array}\right.
$$

where $A$ and $B$ represent coefficient matrixes of the first equation 
(a)
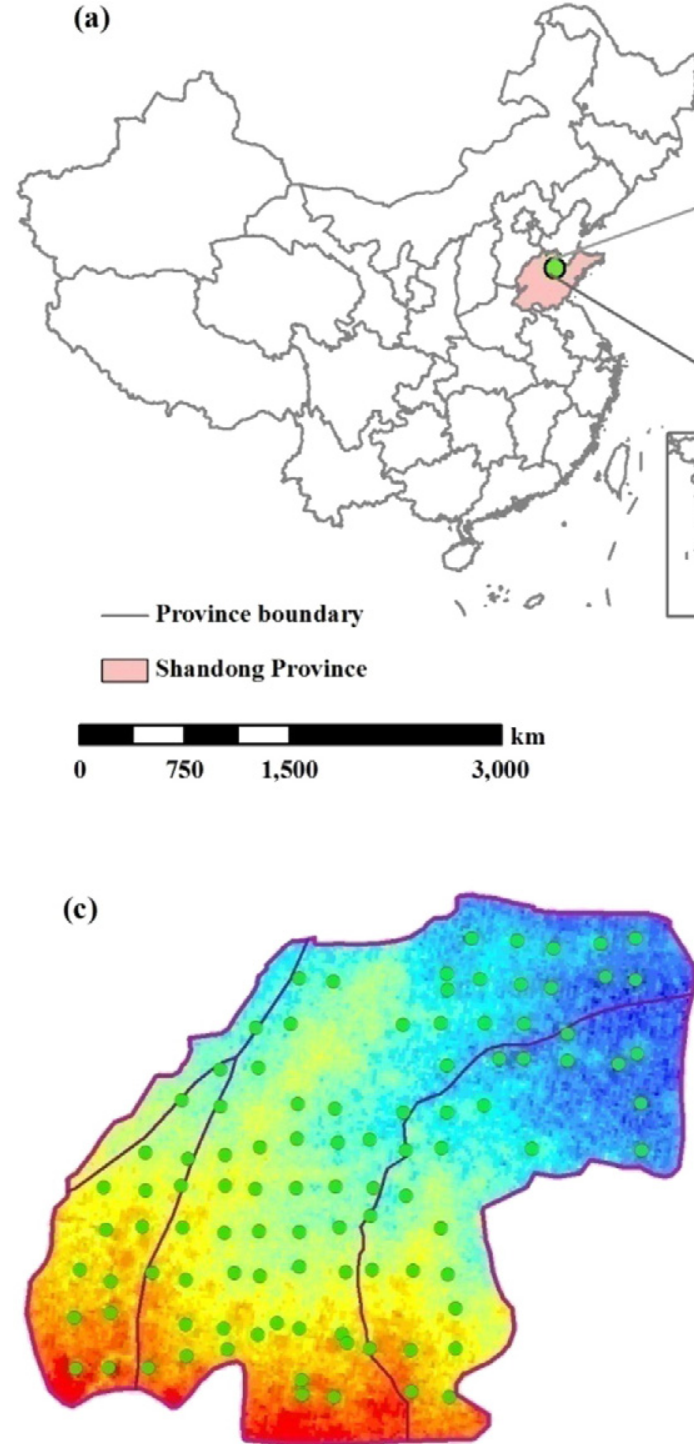

(b)

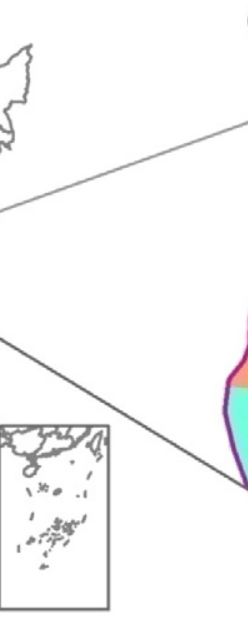

(1)

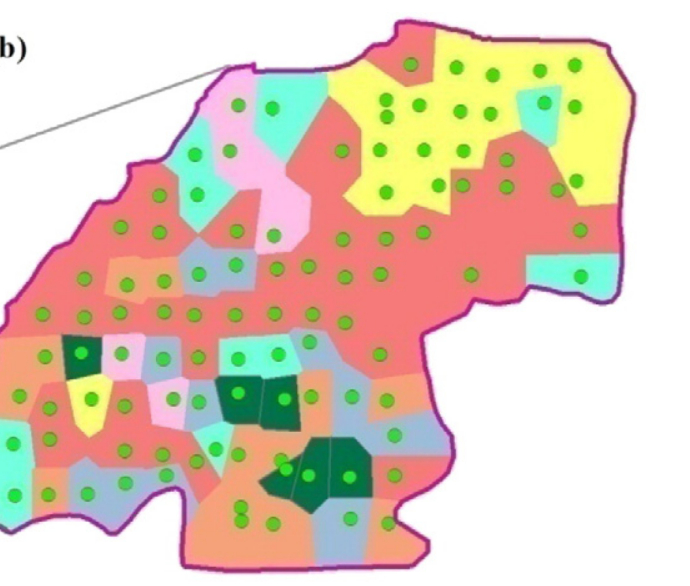

The study area boundary

Different types of vegatables planted

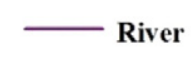

Altitude (m)

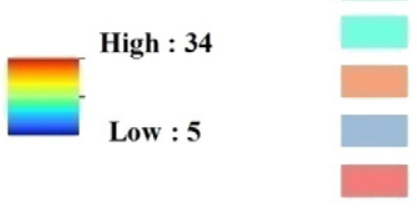

cucumber-cucumber

eggplant

leaf

pepper

tomato-leaf

tomato-melon

tomato-tomato

\begin{tabular}{lll}
0 & 5 & 10 \\
\hline & $\mathrm{km}$
\end{tabular}

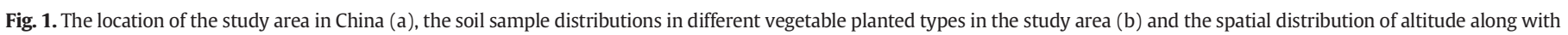
river in the study area (c).

Table 1

The molecular formulas of the studied three types of antibiotics.

\begin{tabular}{|c|c|c|c|}
\hline Antibiotics & Compounds & Chemical formula & Molecular weight \\
\hline Ciprofloxacin (CFX) & & $\mathrm{C}_{17} \mathrm{H}_{18} \mathrm{FN}_{3} \mathrm{O}_{3}$ & 331.34 \\
\hline Norfloxacin (NFX) & & $\mathrm{C}_{16} \mathrm{H}_{18} \mathrm{FN}_{3} \mathrm{O}_{3}$ & 319.34 \\
\hline Enrofloxacin (EFX) & & $\mathrm{C}_{19} \mathrm{H}_{22} \mathrm{FN}_{3} \mathrm{O}_{3}$ & 359.40 \\
\hline
\end{tabular}


Table 2

The stratification for StK based on the vegetable types.

\begin{tabular}{lllll}
\hline $\begin{array}{l}\text { Soil } \\
\text { antibiotics }\end{array}$ & Strata & Vegetable types & $\begin{array}{l}\text { Sampling } \\
\text { number }\end{array}$ & $\begin{array}{l}\text { Total } \\
\text { samplings }\end{array}$ \\
\hline FQs, CFX & I & Pepper & 10 & 40 \\
& & Tomato-leaf & 6 & \\
& & Leaf & 11 & \\
& & Tomato-melon & 17 & 60 \\
& II & Cucumber-cucumber & 17 & \\
& & Tomato-tomato & 38 & \multirow{2}{*}{51} \\
EFX, NFX & I & Eggplant & 5 & \\
& & Tomato-tomato & 38 & \\
& & Tomato-leaf & 13 & 49 \\
& & Cucumber-cucumber & 17 & \\
& II & Pepper & 10 & 5 \\
& Eggplant & 6 & \\
& & Leaf & 11 & \\
& & Tomato-melon & &
\end{tabular}

and the second equation; $c^{n}$ and $d^{n}$ are right-hand side vectors of the two equations respectively; $F^{(n+1)}=\left(f_{1}, 1^{(n+1)}, \cdots\right.$, $\left.f_{(1, J)}^{(n+1)}, \cdots \cdots, f_{(I, 1)}^{(n+1)}, \cdots, f_{(I, J)}^{(n+1)}\right)^{T}(1 \leq i \leq I, 1 \leq j \leq J)$, and $f_{i, j}^{n}$ is the value of the $n$th iteration of $f(x, y)$ at grid cell $\left(x_{i}, y_{i}\right)$.

The solution procedure of HASM, taking the soil sampled values as its constraints, can be transformed into solving the following linear equation set in terms of least squares principle,

$\left\{\begin{array}{c}\min \left[\begin{array}{c}A \\ B\end{array}\right] F^{n+1}-\left[\begin{array}{l}c \\ d\end{array}\right]^{n} 2 \\ S \times F^{n+1}=t\end{array}\right.$

where $n \geq 0, S \in R^{K \times(I \times J)}$ and $t \in R^{K \times 1}$ were sampling matrix and sampling vector, and $K$ is the sampling numbers.

Eq. (2) is to solve the unconstrained least squares problem for a Lagrange parameter $\lambda$, and it is equivalent to the symmetric positive definite linear system,

$$
F^{(n+1)}=\left(A^{T} \cdot A+B^{T} \cdot B+\lambda^{2} \cdot S^{T} \cdot S\right)^{(-1)}\left(A^{T} \cdot c^{n}+B^{T} \cdot d^{n}+\lambda^{2} \cdot S^{T} \cdot k\right)
$$

where $\lambda$ is the weight of the sampling points and determines the contribution of the sampling points to the simulated surface.

Due to the external sources of soil antibiotics, the spatial variation of soil antibiotic residues is different from other soil properties. The algorithm of HASM should be modified according the characters of the spatial distributions of soil antibiotic. There are two aspects needed to be modified on HASM.
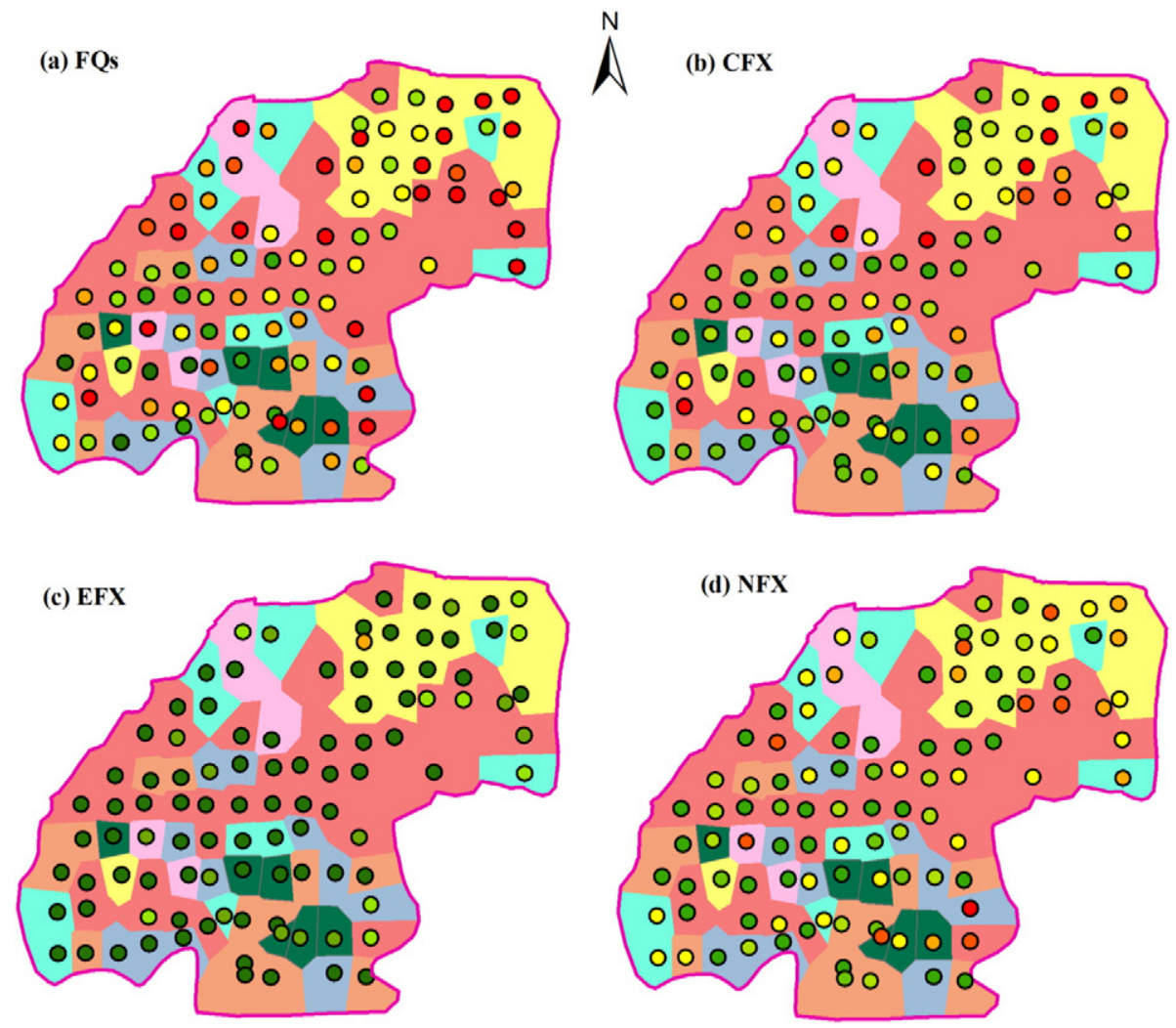

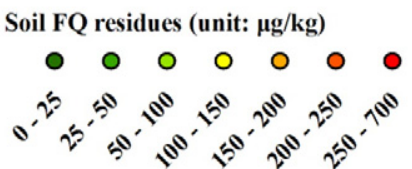

The study area boundary
Different types of vegetables planted

cucumber-cucumber

eggplant

leaf

pepper

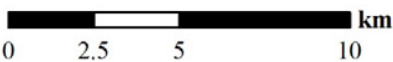

Fig. 2. Spatial variations of soil FQ residues in different vegetable types: total FQs (a), CFX (b), EFX (c) and NFX (d). 
First, because the measurements of soil antibiotics are sparse and poorly correlated in space, combination of environment information with ground measurements can considerably improve simulation accuracy. To combine the vegetable types as secondary information, we take the mean value of the soil antibiotic residues in each vegetable type as global approximate information which is the driving field of HASM, and the soil samplings for antibiotic residues as its optimum control constraints. Thus the iteration initial-values $f_{i, j}^{0}$ of Eq. (3) at the point $\left(x_{i}, y_{i}\right)$ can be achieved according to the types of vegetable planted,

$f_{i, j}^{0}=F_{m}$

where $F_{m}$ is the mean value of the soil antibiotic residues in the vegetable type $m$.
Second, for the large variance of the spatial pattern of soil antibiotics, each soil sampling point should have its own weight in dependent of the variance degree. For the soil sample $\mathrm{k}(k=1,2,3, \cdots, K)$, we compute the variance $V_{k}$ of soil antibiotic residues between the soil sample and its $\mathrm{R}$ neighbor samples, so we can get the variance sequence for each sample points $\left\{V_{1}, V_{2}, V_{3}, \cdots, V_{K}\right\}$. Supposed the maximum and minimum values are $V_{\max }$ and $V_{\min }$, the weight of $k$ th point is,

$\lambda_{k}=\lambda \frac{100 \times V_{\max }-99 \times V_{k}-V_{\min }}{V_{\max }-V_{\min }}$

where $\lambda$ can be supposed as from 1 to 100 , and $R$ can be supposed as from 10 to 20 according to the experience. For the larger variance of the spatial patterns of soil antibiotics, each sampling point affects
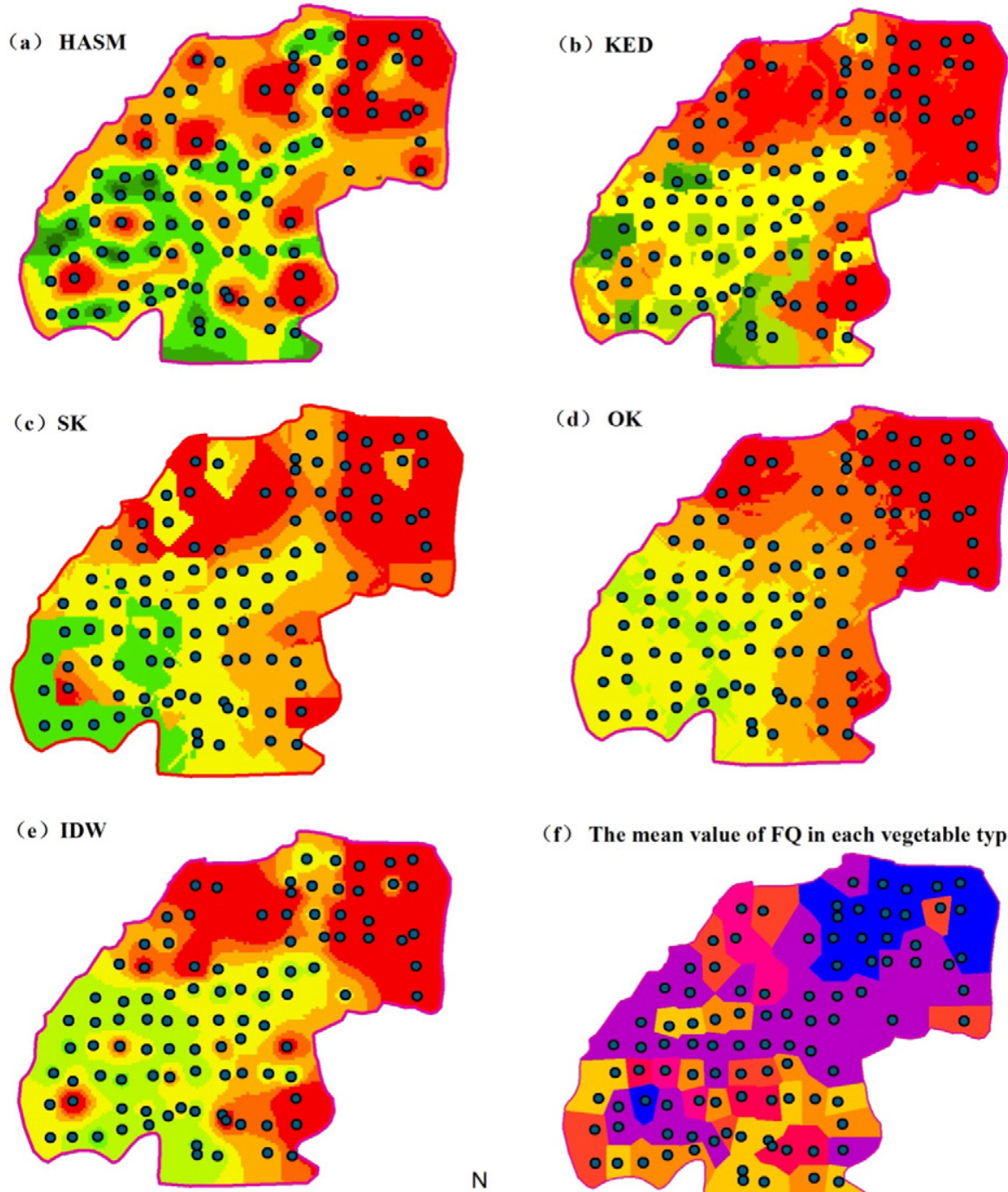

FQ residues $(\mu \mathrm{g} / \mathrm{kg})$

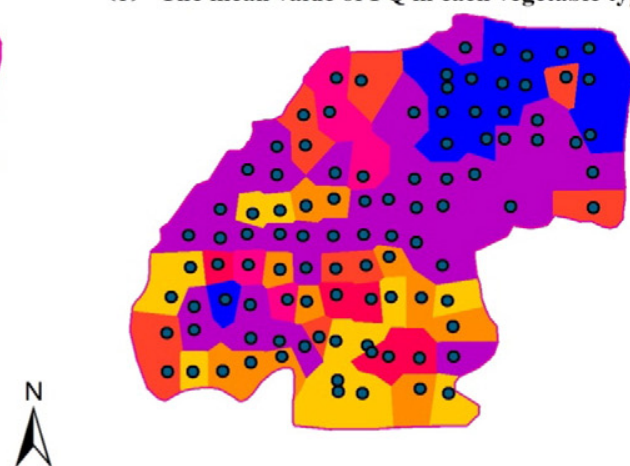

(f) The mean value of FQ in each vegetable type

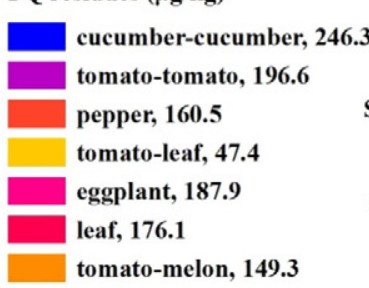

- Soil samplings

The study area boundary
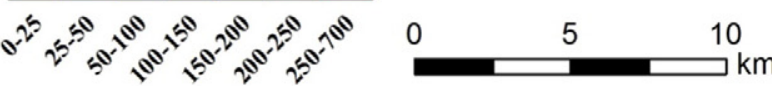
smaller region, so smaller $\lambda$ and $R$ should be chosen; conversely, larger $\lambda$ and $R$ should be used.

\subsection{Kriging with external drift (KED)}

Each observation $z\left(x_{k j}\right)$ on one specific soil property can be expressed as,

$z\left(x_{k j}\right)=m\left(V_{j}\right)+r\left(x_{k j}\right)$

where $x_{k j}$ is the sampling location of $z\left(x_{k j}\right)$, which is the $k$ th sampling points on the $j$ th vegetable type $V_{j}, m\left(V_{j}\right)$ is the mean value of $z\left(x_{k j}\right)$ for each vegetable type $V_{j}$, and $r\left(x_{k j}\right)$ is the residual computed by subtracting the average soil antibiotic of the relative vegetation type from the original value of each soil antibiotic. We assume that $m\left(V_{j}\right)$ and $r\left(x_{k j}\right)$ are independent mutually and the variation of $r\left(x_{k j}\right)$ is homogeneous over the whole study area. The residuals are then used to interpolate the surface of residuals in the whole study area by OK, respectively. The interpolated values of residuals are finally summed to the soil antibiotic averages of the relevant vegetable types as the final interpolated values of KED.

\subsection{Stratified kriging (StK)}

StK is another kriging method which can be combined with categorical variable (Shi et al., 2011). The stratification was based on vegetable types in this study. Each separate variogram was computed for each stratum, and only the data for the same types were used to interpolate within those vegetable types. Because the method needs enough soil samplings to compute the variograms for each stratum, we stratified
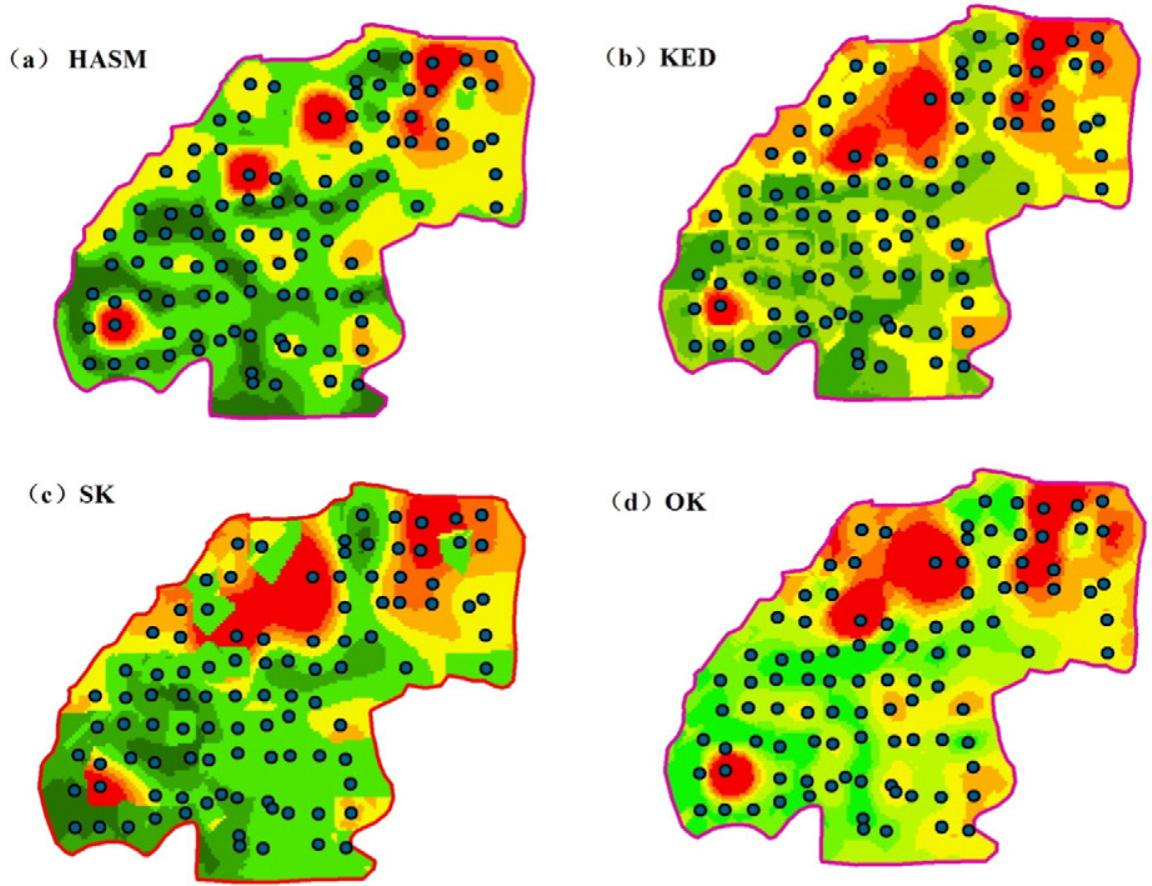

(e) IDW

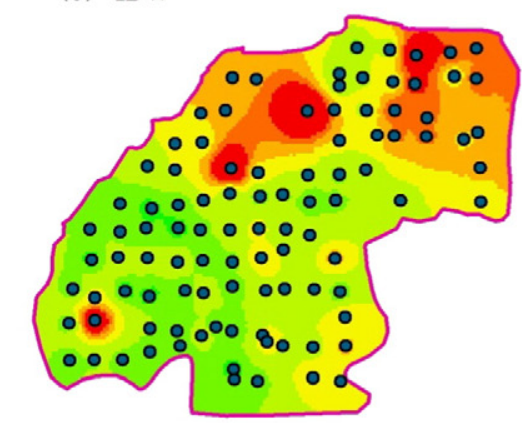

CFX residues $(\mu \mathrm{g} / \mathrm{kg})$

(f) The mean value of CFX in each vegatable type

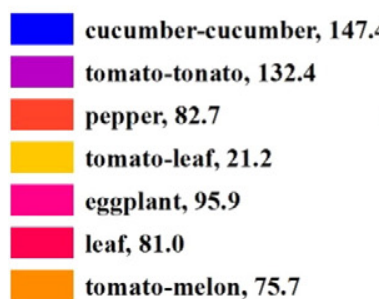

Soil CFX residues $(\mu \mathrm{g} / \mathrm{kg})$

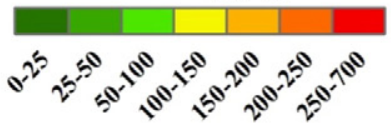

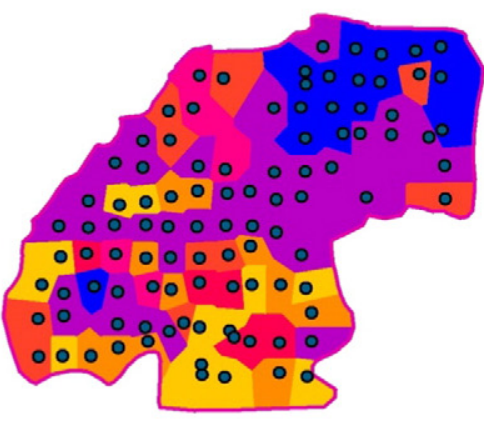

- Soil samplings

The study area boundary

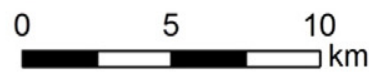


the whole area into two strata according to the local mean values for each vegetable type for the interpolation of FQs, CFX, EFX and NFX. The stratification and the soil sampling amounts for each stratum were shown in Table 2.

\subsection{OK and IDW}

OK and IDW were also used for the interpolation of soil FQs. We employed them to compare their performance with that of HASM method. The best parameters for both OK and IDW were decided by choosing the smallest root mean squared error (RMSE) statistic. For OK, different models were fitted using weighted least squares, and the model with the smallest residual sum of squares (RSS) was chosen. For IDW, we also choose the powers of 1,2,3, and 4 for the best accuracy. For the number of the closest samples of OK and IDW, the best one from 5 to 30 with 5 step interval was chosen.

\subsection{Validation}

Cross-validation is the usual methods of validation for comparing the interpolation methods. It involves eliminating each observation of soil antibiotic in turn, estimating the soil antibiotic value at its site from the remaining observations and comparing the predicted value with the measured value. We used the most common indices, the mean absolute error (MAE) and the root mean square error (RMSE) as the measures of interpolation quality (Shi et al., 2009; Shi et al., 2011; Shi et al., 2012).
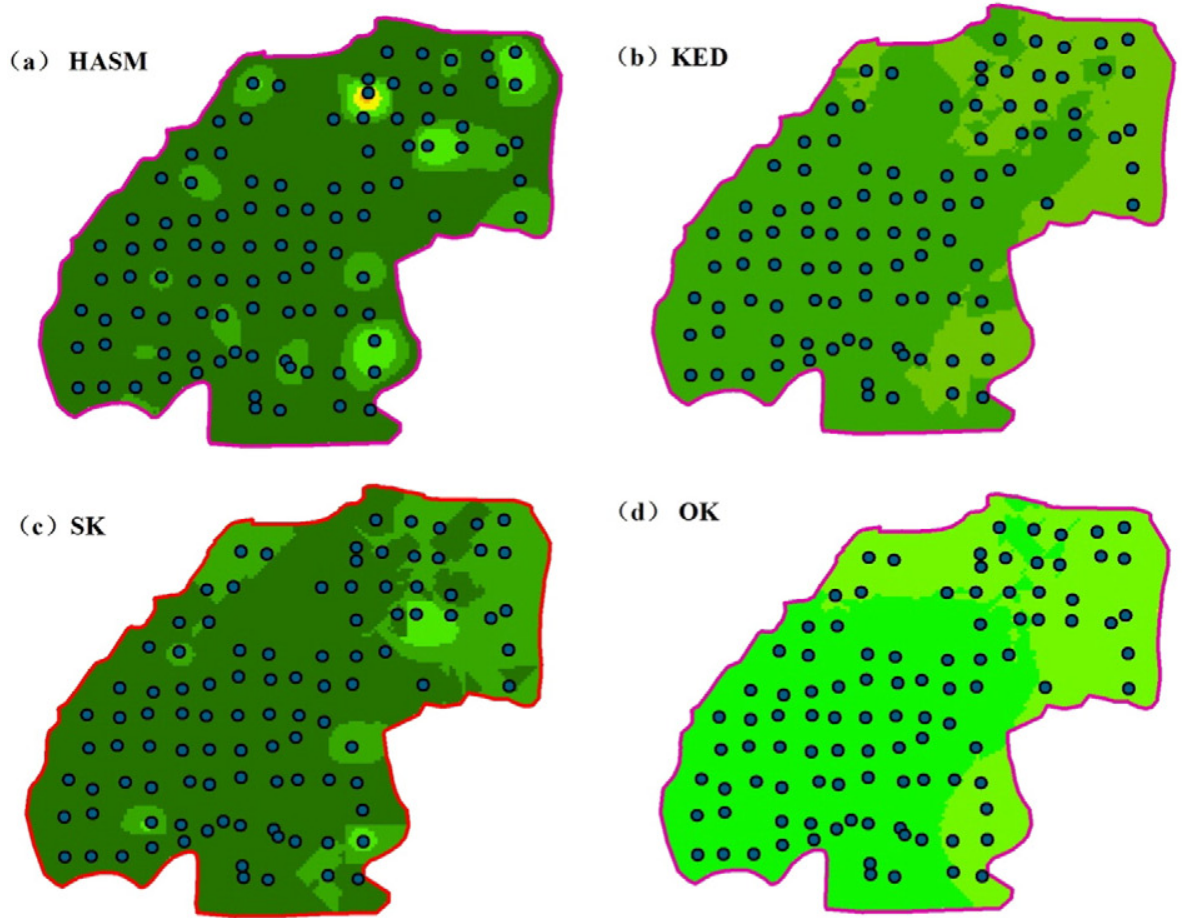

(d) $\mathrm{OK}$

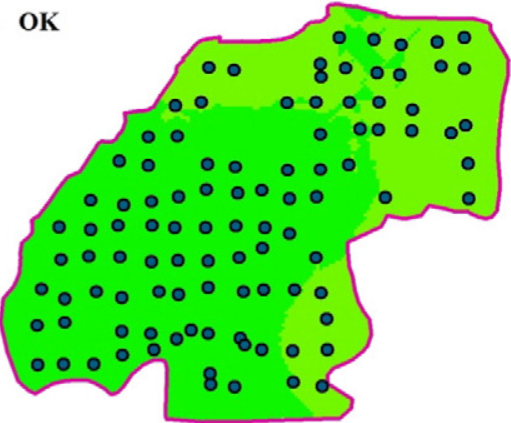

(e) IDW

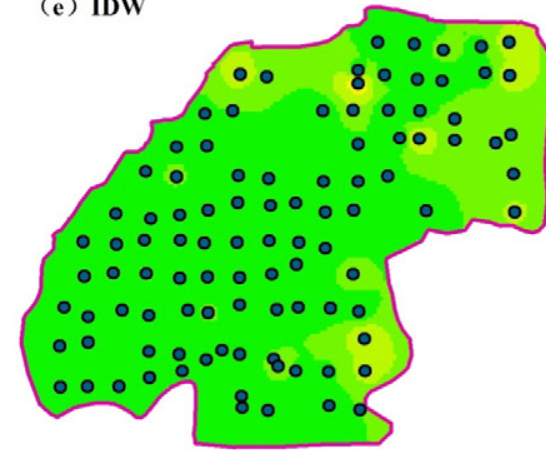

EFX residues $(\mu \mathrm{g} / \mathrm{kg})$

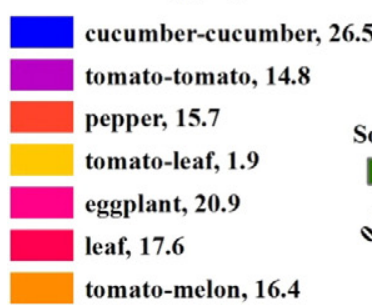

(f) The mean value of EFX in each vegatable type

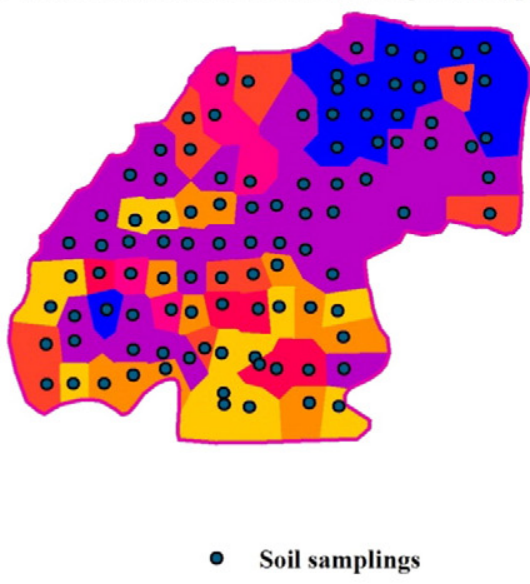

oil EFX residues $(\mu \mathrm{g} / \mathrm{kg})$

The study area boundary

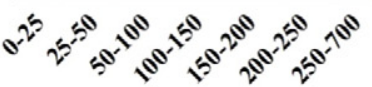

5

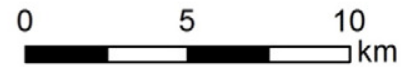


As there are $n$ sites belonging to the validation sample set, MAE and RMSE are determined from the measured values $z\left(x_{i}\right)$ and the interpolated value $z^{*}\left(x_{i}\right)$. They are given by,

$\mathrm{MAE}=\frac{1}{n} \sum_{i=1}^{n}\left[\left|z *\left(x_{i}\right)-z\left(x_{i}\right)\right|\right]$

RMSE $=\sqrt{\frac{1}{n} \sum_{i=1}^{n}\left[z *\left(x_{i}\right)-z\left(x_{i}\right)\right]^{2}}$.

The MAE and RMSE are measures of the accuracy of interpolation which should be as small as possible for accurate interpolation.
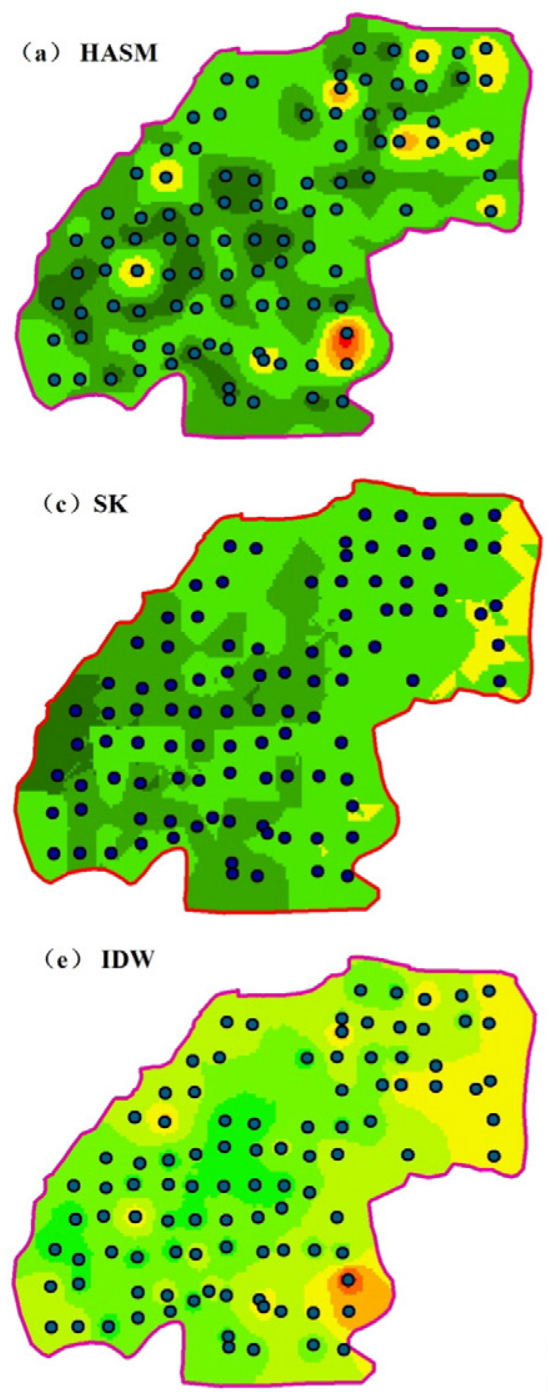

NFX residues $(\mu \mathrm{g} / \mathrm{kg})$

cucumber-cucumber, 72.3

tomato-tomato, 49.4

pepper, 62.1

tomato-leaf, 27.6

eggplant, 71.1

leaf, 77.5

tomato-melon, 60.1

\section{Results}

\subsection{The spatial variations of soil FQ concentrations}

The spatial distributions of soil FQ residues show large variations in different planted vegetable types (Fig. 2). In the cucumber-cucumber planted soil, FQ residues show the highest average concentration with $246.3 \pm 181.5 \mu \mathrm{g} / \mathrm{kg}$, and followed by those in tomato-tomato (196.6 $\pm 168.3 \mu \mathrm{g} / \mathrm{kg})$, eggplant (187.9 $\pm 117.1 \mu \mathrm{g} / \mathrm{kg})$, leaf $(176.1 \pm$ $102.9 \mu \mathrm{g} / \mathrm{kg}$ ), pepper $(160.5 \pm 73.0 \mu \mathrm{g} / \mathrm{kg})$ and tomato-melon $(149.3 \pm 140.7 \mu \mathrm{g} / \mathrm{kg}$ ) planted areas (Table 2 ). The highest FQ residues are found in the samples collected from cucumber-cucumber and tomato-tomato planted areas, which are more than $650 \mu \mathrm{g} / \mathrm{kg}$ (Table 2). This is because the maximums of the soil CFX in these two vegetable types are $493.4 \mu \mathrm{g} / \mathrm{kg}$ and $651.6 \mu \mathrm{g} / \mathrm{kg}$, respectively. The averages of
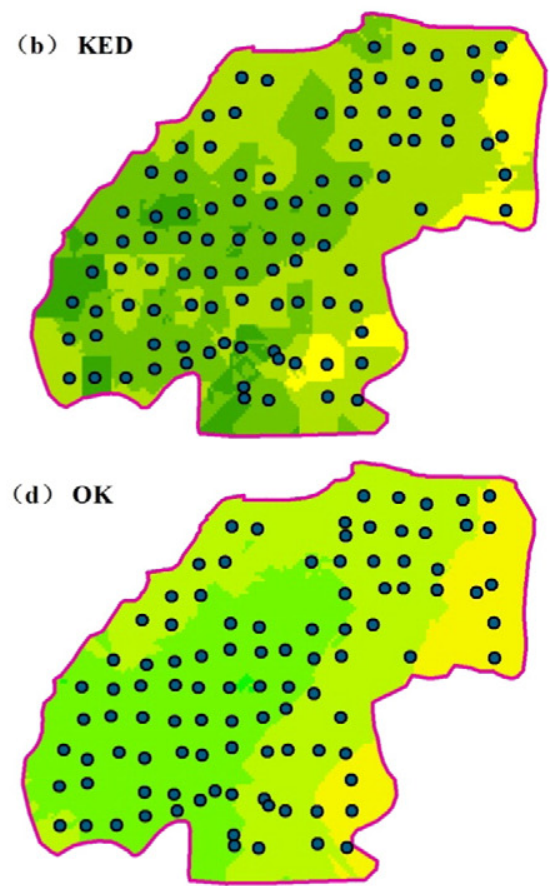

(f) The mean value of NFX in each vegatable type

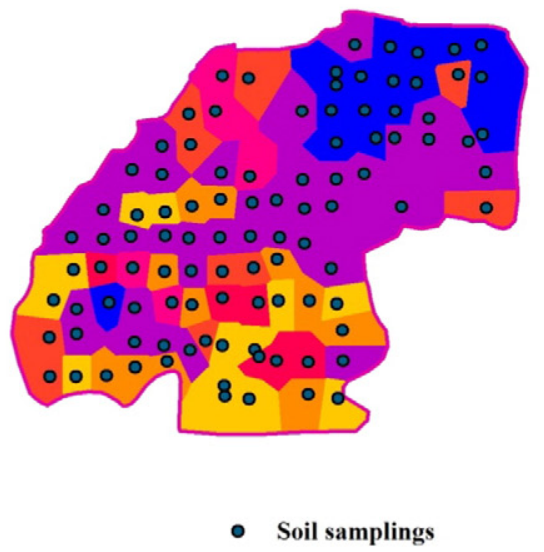

Soil NFX residues $(\mu \mathrm{g} / \mathrm{kg})$

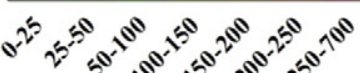

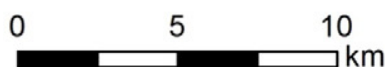


soil CFX in the two types are also the highest, which are $147.5 \mu \mathrm{g} / \mathrm{kg}$ and $132.4 \mu \mathrm{g} / \mathrm{kg}$, respectively. The average of soil EFX is less compared with the other two soil FQs, but the coefficients of variation are larger than $100 \%$ only except for pepper and leaf planted areas. The maximum of soil NFX is found in tomato-melon planted areas $(288.3 \mu \mathrm{g} / \mathrm{kg})$, and cucumber-cucumber and tomato-tomato followed with $206.3 \mu \mathrm{g} / \mathrm{kg}$ and $206.0 \mu \mathrm{g} / \mathrm{kg}$.

Table 4 showed the analysis of variances to compare the effects of different vegetable types on the tested soil antibiotics. We found that the variances of soil FQs and CFX among the vegetable types were significant at 0.05 level, but that of NFX and EFX were not significant. ANOVA analysis revealed that variances of the tested soil antibiotics among vegetable types especially in soil FQs and CFX might play an important role in their spatial prediction in the study area.

Soil FQ residues in tomato-leaf are the lowest with average of $47.4 \mu \mathrm{g} / \mathrm{kg}$, which may be due to the high absorption by leaf especially by spinach for soil NFX and EFX with $411 \mu \mathrm{g} / \mathrm{kg}$ and $24.1 \mu \mathrm{g} / \mathrm{kg}$ (Li et al., 2014). The variation of soil FQs in different vegetable planted areas may be due to the different sources of manure with antibiotics from different animal breeding (Bound and Voulvoulis, 2004; Li et al., 2013).

\subsection{Comparisons of the performance of HASM, KED, StK, OK and IDW}

We used a consistent cross-validation method to test HASM, KED, StK, OK and IDW results, and computed MAE and RMSE to compare the performance of different interpolators (Table 5). The results indicate that HASM is the most accurate technique, which performs better for the two indices than KED, StK, OK, and IDW. The methods combined with vegetable types, including HASM, KED and StK, achieve less errors especially in the interpolations for FQs and CFX, indicating that vegetable type should be considered as a key factor in the prediction of the spatial patterns of soil antibiotics.
The MAEs of HASM for FQs, CFX, EFX and NFX are almost half of those of the other four interpolators, and KED and StK which are also combined with the vegetable type information perform better than OK and IDW especially in FQs and CFX. For example, the MAE of HASM for FQs is $55.1 \mu \mathrm{g} / \mathrm{kg}$, and the MAEs of KED, StK, OK and IDW are $99.0 \mu \mathrm{g} / \mathrm{kg}, 102.8 \mu \mathrm{g} / \mathrm{kg}, 106.3 \mu \mathrm{g} / \mathrm{kg}$ and $108.7 \mu \mathrm{g} / \mathrm{kg}$, respectively. For CFX (EFX and NFX), MAEs of HASM, KED, StK, OK and IDW are 34.8 (8.9 and 23.4) $\mu \mathrm{g} / \mathrm{kg}, 70.8$ (15.4 and 40.0) $\mu \mathrm{g} / \mathrm{kg}, 67.4$ (16.4 and $41.6) \mu \mathrm{g} / \mathrm{kg}, 75.1$ (15.6 and 42.1) $\mu \mathrm{g} / \mathrm{kg}$ and 72.7 (16.8 and 45.1) $\mu \mathrm{g} / \mathrm{kg}$, respectively. RMSE is the other error index to compare different interpolators, which also shows that HASM performs the best. The RMSE results show that HASM for FQs, CFX, EFX and NFX are $106.2 \mu \mathrm{g} / \mathrm{kg}$, $88.6 \mu \mathrm{g} / \mathrm{kg}, 20.4 \mu \mathrm{g} / \mathrm{kg}$ and $39.2 \mu \mathrm{g} / \mathrm{kg}$, respectively; those of KED (StK, OK and IDW) for FQs, CFX, EFX and NFX are $138.3 \mu \mathrm{g} / \mathrm{kg}(141.4 \mu \mathrm{g} / \mathrm{kg}$, $146.1 \mu \mathrm{g} / \mathrm{kg}, 150.9 \mu \mathrm{g} / \mathrm{kg}), 112.3 \mu \mathrm{g} / \mathrm{kg}(112.6 \mu \mathrm{g} / \mathrm{kg}, 118.3 \mu \mathrm{g} / \mathrm{kg}$, $116.9 \mu \mathrm{g} / \mathrm{kg}), 24.8 \mu \mathrm{g} / \mathrm{kg}(26.0 \mu \mathrm{g} / \mathrm{kg}, 25.1 \mu \mathrm{g} / \mathrm{kg}, 27.6 \mu \mathrm{g} / \mathrm{kg})$ and $53.5 \mu \mathrm{g} / \mathrm{kg}(56.2 \mu \mathrm{g} / \mathrm{kg}, 55.2 \mu \mathrm{g} / \mathrm{kg}, 59.1 \mu \mathrm{g} / \mathrm{kg})$.

\subsection{Comparisons of the interpolated maps by HASM, KED, StK, OK and IDW}

We mapped the distributions of FQs, CFX, EFX and NFX by HASM, KED, StK, OK and IDW (Figs. 3, 4, 5 and 6) to compare the mapping details of the five interpolators. In general, the methods of HASM (Figs. 3a, 4a, 5a and 6a), KED (Figs. 3b, 4b, 5b and 6b) and StK (Figs. 3c, 4c, 5c and $6 \mathrm{c}$ ) combined with the vegetable type information (Figs. 3f, $4 \mathrm{f}, 5 \mathrm{f}$ and 6f) perform better with more details in the interpolations. For example, the interpolation maps of HASM, KED and StK have better relationship with the vegetable types especially for the FQs and CFX, which has proved the results of geostatistical analysis and the error comparisons in the above sections. In addition, the statistical values of maps by HASM are more consistent with the measured data (Fig. 2a, b, c and d). Although the spatial patterns of the five techniques have similar tendency of spatial distributions in the whole study area, maps interpolated by HASM have more consistent maximum and minimum values of FQs,

Table 3

Statistical analysis of soil FQ concentrations in different vegetable types (unit: $\mu \mathrm{g} / \mathrm{kg}$ ).

\begin{tabular}{|c|c|c|c|c|c|c|c|c|c|c|}
\hline Soil antibiotics & Vegetable types & $\mathrm{N}$ & Mean & SD & $\mathrm{CV}$ & Min & Median & Max & Skewness & Kurtosis \\
\hline \multirow[t]{8}{*}{ FQs } & All & 100 & 175.2 & 151.1 & 86.2 & 9.1 & 132.2 & 682.7 & 1.5 & 1.9 \\
\hline & Cucumber-cucumber & 17 & 246.3 & 181.5 & 73.7 & 29.3 & 171.9 & 682.7 & 0.9 & 0.2 \\
\hline & Tomato-tomato & 38 & 196.6 & 168.3 & 85.6 & 16.8 & 135.7 & 669.3 & 1.4 & 1.2 \\
\hline & Pepper & 10 & 160.5 & 73.0 & 45.5 & 99.7 & 150.6 & 343.5 & 2.0 & 4.6 \\
\hline & Tomato-leaf & 13 & 47.4 & 20.2 & 42.6 & 19.1 & 55.3 & 75.8 & -0.3 & -1.7 \\
\hline & Eggplant & 5 & 187.9 & 117.1 & 62.3 & 12.3 & 234.2 & 284.8 & -1.0 & -0.5 \\
\hline & Leaf & 6 & 176.1 & 102.9 & 58.4 & 34.5 & 176.3 & 343.2 & 0.5 & 1.2 \\
\hline & Tomato-melon & 11 & 149.3 & 140.7 & 94.2 & 9.1 & 129.9 & 528.3 & 2.2 & 5.8 \\
\hline \multirow[t]{8}{*}{ CFX } & All & 100 & 104.4 & 117.5 & 112.5 & 2.4 & 72.4 & 651.6 & 2.7 & 8.7 \\
\hline & Cucumber-cucumber & 17 & 147.4 & 130.2 & 88.3 & 2.4 & 84.5 & 493.4 & 1.3 & 1.6 \\
\hline & Tomato-tomato & 38 & 132.4 & 152.2 & 114.9 & 5.9 & 88.7 & 651.6 & 2.3 & 5.4 \\
\hline & Pepper & 10 & 82.7 & 53.1 & 64.2 & 16.1 & 92.7 & 165.5 & 0.1 & -1.4 \\
\hline & Tomato-leaf & 13 & 21.2 & 12.3 & 58.3 & 7.5 & 17.4 & 43.4 & 0.7 & -0.7 \\
\hline & Eggplant & 5 & 95.9 & 54.6 & 56.9 & 11.0 & 110.5 & 153.7 & -1.0 & 1.0 \\
\hline & Leaf & 6 & 81.0 & 40.1 & 49.5 & 21.1 & 78.5 & 144.0 & 0.2 & 1.5 \\
\hline & Tomato-melon & 11 & 75.7 & 47.4 & 62.7 & 19.8 & 66.7 & 146.7 & 0.3 & -1.6 \\
\hline \multirow[t]{8}{*}{ EFX } & All & 100 & 15.8 & 25.5 & 161.4 & 0 & 7.0 & 167.0 & 3.2 & 13.3 \\
\hline & Cucumber-cucumber & 17 & 26.5 & 42.4 & 160.0 & 0.3 & 15.7 & 167.0 & 2.6 & 7.6 \\
\hline & Tomato-tomato & 38 & 14.8 & 21.7 & 146.8 & 0.0 & 6.9 & 98.8 & 2.2 & 5.3 \\
\hline & Pepper & 10 & 15.7 & 14.9 & 94.8 & 2.5 & 9.5 & 51.8 & 1.9 & 3.6 \\
\hline & Tomato-leaf & 13 & 1.9 & 2.1 & 110.7 & 0.0 & 1.3 & 6.4 & 1.1 & 0.6 \\
\hline & Eggplant & 5 & 20.9 & 24.4 & 116.4 & 0.0 & 15.2 & 57.9 & 1.0 & 0.0 \\
\hline & Leaf & 6 & 17.6 & 14.0 & 80.0 & 1.2 & 15.7 & 40.7 & 0.8 & 0.4 \\
\hline & Tomato-melon & 11 & 16.4 & 28.3 & 172.8 & 0.0 & 3.4 & 93.3 & 2.4 & 6.0 \\
\hline \multirow[t]{8}{*}{ NFX } & All & 100 & 55.7 & 56.4 & 101.3 & 0.4 & 33.3 & 288.3 & 1.6 & 2.7 \\
\hline & Cucumber-cucumber & 17 & 72.3 & 61.2 & 84.6 & 8.8 & 47.7 & 206.3 & 0.9 & -0.4 \\
\hline & Tomato-tomato & 38 & 49.4 & 55.6 & 112.5 & 0.4 & 26.3 & 206.0 & 1.6 & 1.5 \\
\hline & Pepper & 10 & 62.1 & 38.8 & 62.4 & 12.7 & 55.6 & 149.5 & 1.2 & 2.2 \\
\hline & Tomato-leaf & 13 & 27.6 & 20.0 & 72.5 & 7.2 & 26.9 & 75.7 & 1.2 & 1.4 \\
\hline & Eggplant & 5 & 71.1 & 72.8 & 102.3 & 1.3 & 73.2 & 171.2 & 0.4 & -1.3 \\
\hline & Leaf & 6 & 77.5 & 51.7 & 66.8 & 12.2 & 77.9 & 158.5 & 0.4 & 0.1 \\
\hline & Tomato-melon & 11 & 60.1 & 81.3 & 135.4 & 9.1 & 31.5 & 288.3 & 2.6 & 7.3 \\
\hline
\end{tabular}


Table 4

ANOVA analysis for testing the significance of vegetable type effects on the variances of soil antibiotics.

\begin{tabular}{|c|c|c|c|c|c|c|}
\hline Soil property & Source of variance & df & Sum of squares & Mean square & F value & Sig. \\
\hline \multirow[t]{3}{*}{$\mathrm{FQ}, \mu \mathrm{g} / \mathrm{kg}$} & Between vegetation types & 6 & $325,986.08$ & $54,331.01$ & 2.61 & $<0.05^{*}$ \\
\hline & Within vegetation types & 93 & $1,933,382.29$ & $20,789.06$ & & \\
\hline & Total & 99 & $2,259,368.36$ & & & \\
\hline \multirow[t]{3}{*}{$\mathrm{NFX}, \mu \mathrm{g} / \mathrm{kg}$} & Between vegetation types & 6 & $21,075.47$ & 3512.58 & 1.11 & 0.36 \\
\hline & Within vegetation types & 93 & $293,487.92$ & 3155.78 & & \\
\hline & Total & 99 & $314,563.39$ & & & \\
\hline \multirow[t]{3}{*}{ CFX, $\mu \mathrm{g} / \mathrm{kg}$} & Between vegetation types & 6 & $168,871.08$ & $28,145.18$ & 2.19 & $<0.05^{*}$ \\
\hline & Within vegetation types & 93 & $1,197,971.04$ & $12,881.49$ & & \\
\hline & Total & 99 & $1,366,842.12$ & & & \\
\hline \multirow[t]{3}{*}{$\mathrm{EFX}, \mu \mathrm{g} / \mathrm{kg}$} & Between vegetation types & 6 & 4658.58 & 776.43 & 1.21 & 0.31 \\
\hline & Within vegetation types & 93 & $59,477.27$ & 639.54 & & \\
\hline & Total & 99 & $64,135.85$ & & & \\
\hline
\end{tabular}

* Significant at the 0.05 level.

CFX, EFX and NFX with those of measured data (Table 3) than the other four methods. In the opposite, OK (Figs. 3d, 4d, 5d and 6d) and IDW (Figs. 3e, 4e, 5e and 6e) over-estimate the FQs of soil samples especially between the range of $0-25 \mu \mathrm{g} / \mathrm{kg}$.

The interpolation maps from HASM show the spatial patterns and pollution assessment of soil antibiotics clearly in the Figs. 3a, 4a, 5a and $6 a$. About $50 \%$ area of soil FQ concentrations are greater than $165 \mu \mathrm{g} / \mathrm{kg}$ (Fig. 3a), indicating that half of the study area has been polluted by soil antibiotics according to the technical guidance specified in the European registration procedure for human and veterinary medicines. The main polluted source is from CFX, which has resulted in $44 \%$ area greater than $100 \mu \mathrm{g} / \mathrm{kg}$ with a certain trigger value for soil (Fig. 4a). Most of the polluted area distributes in the northeast of the study area, where cucumbers and tomatoes were planted. Soil EFX residues are lower than $25 \mu \mathrm{g} / \mathrm{kg}$ in most of the study area (Fig. 5a). Soil NFX residues in $50 \%$ of the study areas are lower than $50 \mu \mathrm{g} / \mathrm{kg}$ (Fig. 6a). We can find that higher concentrations of CFX residual and lower concentrations of EFX residues are always together presented in the study area. This may be because metabolic conversion of EFX into CFX occurs in many species' metabolism which has been reported in many references (Zhao et al., 2010; Li et al., 2013). In addition, there may be also other factors affected the distributions of soil antibiotics. For example, the accumulation and distribution of hydrophilic antibiotics may be driven by water movement. Higher FQ residues are distributed in the southeast where is in the Lower River region with lower altitude in the study area (Fig. 1c).

\section{Conclusions and discussion}

Antibiotics are substances from extraneous sources into soils, which results in large variance related to the manure application and the absorption of the vegetable planted. A surface modeling method for the interpolation of soil antibiotic residues is being developed on the basis of HASM, which takes the information of vegetable types as driving field and different weight of sampling points as its optimum control constraints. The validation results show that HASM always has the highest accuracy in the interpolation of soil antibiotic residues when compared with not only the methods combined categorical information like KED

Table 5

The MAEs and RMSEs of cross-validation for HASM, KED, StK, OK and IDW (unit: $\mu \mathrm{g} / \mathrm{kg}$ ).

\begin{tabular}{llrrrrr}
\hline Soil antibiotics & Indices & HASM & \multicolumn{1}{c}{ KED } & \multicolumn{1}{c}{ StK } & \multicolumn{1}{c}{ OK } & IDW \\
\hline FQs & MAE & 55.1 & 99.0 & 102.8 & 106.3 & 108.7 \\
& RMSE & 106.2 & 138.3 & 141.4 & 146.1 & 150.9 \\
CFX & MAE & 34.8 & 70.8 & 67.4 & 75.1 & 72.7 \\
& RMSE & 88.6 & 112.3 & 112.6 & 118.3 & 116.9 \\
EFX & MAE & 8.9 & 15.4 & 16.4 & 15.6 & 16.8 \\
& RMSE & 20.4 & 24.8 & 26.0 & 25.1 & 27.6 \\
NFX & MAE & 23.4 & 40.0 & 41.6 & 42.1 & 45.1 \\
& RMSE & 39.2 & 53.5 & 56.2 & 55.2 & 59.1 \\
\hline
\end{tabular}

and StK, but also IDW and OK. Furthermore, HASM can interpolate soil antibiotics according to the similarity degree of vegetable planted types and variation degree among the antibiotic residues in soil samples, which can present reasonable results and show more details of the spatial distributions of soil antibiotics.

There are three reasons for better performance of the modified HASM when predicts the spatial pattern of soil antibiotics. First, HASM takes the vegetable type information as global approximate information, and takes local sampling data as its optimum control constraints. Second, spatial heterogeneity of the neighbor samplings were considered in the prediction. Third, the output of HASM satisfies the iteration stopping criterion which is determined by application requirement for accuracy.

When HASM is used in modeling spatial distributions of soil antibiotics, choosing the ancillary information appropriately is the most important step before the interpolation. The relationship between the affected factors and the spatial patterns on soil antibiotic residues should be analyze, so the most related factor can be chosen as the ancillary information.

Surface modeling of soil antibiotic residues is essential for risk assessment of the soil pollution, especially for the estimation of the higher values of soil antibiotic residues. The future work of soil antibiotic interpolation should be combined with more dynamic mechanism of soil antibiotic in soil-plant system for adding more optimum control conditions to achieve more accuracy maps.

\section{Acknowledgments}

Thanks for the support by the State Key Laboratory of Resources and Environmental Information System. This study was supported by the National Natural Science Foundation of China (41371002, 91325204 and 41421001) and Promotive Research Fund for Excellent Young and Middle-aged Scientists of Shandong Province (BS2013NY008). We gratefully acknowledge the anonymous reviewers and the editor for their insightful comments, suggestions and language revisions.

\section{References}

Aust, M.O., Godlinski, F., Travis, G.R., Hao, X., McAllister, T.A., Leinweber, P., Thiele-Bruhn, S., 2008. Distribution of sulfamethazine, chlortetracycline and tylosin in manure and soil of Canadian feedlots after subtherapeutic use in cattle. Environ. Pollut. 156, 1243-1251.

Bound, J., Voulvoulis, N., 2004. Pharmaceuticals in the aquatic environment: a comparison of risk assessment strategies. Chemosphere 56, 1143-1155.

Goovaerts, P., 1999. Geostatistics in soil science: state-of-the-art and perspectives. Geoderma 89, 1-45.

Gotway, C.A., Ferguson, R.B., Hergert, G.W., Peterson, T.A., 1996. Comparison of kriging and inverse-distance methods for mapping soil parameters. Soil Sci. Soc. Am. J. 60, 1237-1247.

Kuchta, S.L., Cessna, A.J., 2009. Lincomycin and spectinomycin concentrations in liquid swine manure and their persistence during simulated manure storage. Arch. Environ. Contam. Toxicol. 57, 1-10. 
Li, X., Xie, Y., Wang, J., Christakos, G., Si, J., Zhao, H., Ding, Y., Li, J., 2013. Influence of planting patterns on fluoroquinolone residues in the soil of an intensive vegetable cultivation area in northern China. Sci. Total Environ. 458-460, 63-69.

Li, X., Xie, Y., Li, C., Zhao, H., Zhao, H., Wang, N., Wang, J., 2014. Investigation of residual fluoroquinolones in a soil-vegetable system in an intensive vegetable cultivation area in Northern China. Sci. Total Environ. 468-469, 258-264.

Martínez-Carballo, E., González-Barreiro, C., Scharf, S., Gans, O., 2007. Environmenta monitoring study of selected veterinary antibiotics in animal manure and soils in Austria. Environ. Pollut. 148, 570-579.

Panagopoulos, T., Jesus, J., Antunes, M.D.C., Beltrao, J., 2006. Analysis of spatial interpolation for optimising management of a salinized field cultivated with lettuce. Eur. J. Agron. 24, 1-10.

Sarmah, A.K., Meyer, M.T., Boxall, A., 2006. A global perspective on the use, sales, exposure pathways, occurrence, fate and effects of veterinary antibiotics (VAs) in the environment. Chemosphere 65, 725-759.

Shi, W., Liu, J., Du, Z., Song, Y., Chen, C., Yue, T., 2009. Surface modelling of soil pH. Geoderma 150, 113-119.

Shi, W., Liu, J., Du, Z., Stein, A., Yue, T., 2011. Surface modelling of soil properties based on land use information. Geoderma 162, 347-357.

Shi, W., Liu, J., Du, Z., Yue, T., 2012. Development of a surface modeling method for mapping soil properties. J. Geogr. Sci. 22, 752-760.

Stein, A., Corsten, L.C.A., 1991. Universal kriging and cokriging as a regression procedure Biometrics 47, 575-587.
Stein, A., Hoogerwerf, M., Bouma, J., 1988. Use of soil-map delineations to improve (Co)kriging of point data on moisture deficits. Geoderma 43, 163-177.

Weber, D.D., Englund, E.J., 1992. Evaluation and comparison of spatial interpolators. Math. Geol. 24, 381-391.

Weber, D.D., Englund, E.J., 1994. Evaluation and comparison of spatial interpolators II. Math. Geol. 26, 589-603.

Webster, R., Oliver, M.A., 2001. Geostatistics for Environmental Scientists. John Wiley and Sons, West Sussex, England.

Xie, Y.F., Li, X.W., Wang, J.F., Christakos, G., Hu, M.G., An, L.H., Li, F.S., 2012. Spatial estimation of antibiotic residues in surface soils in a typical intensive vegetable cultivation area in China. Sci. Total Environ. 430, 126-131.

Yue, T.X., 2011. Surface Modeling: High Accuracy and High Speed Methods. CRC Press, New York.

Yue, T.X., Zhao, N., Ramsey, R.D., Wang, C.L., Fan, Z.M., Chen, C.F., Lu, Y.M., Li, B.L., 2013. Climate change trend in China, with improved accuracy. Clim. Chang. 120, 137-151.

Yue, T.X., Zhao, M.W., Zhang, X.Y., 2014. A high-accuracy method for filling voids on remotely sensed XCO2 surfaces and its verification. J. Clean. Prod. 106, 819-827.

Yue, T.X., Zhang, L., Zhao, N., Zhao, M., Chen, C., Du, Z., et al., 2015. A review of recent developments in HASM. Environ. Earth Sci. 74 (8), 6541-6549.

Zhao, L., Dong, Y.H., Wang, H., 2010. Residues of veterinary antibiotics in manures from feedlot livestock in eight provinces of China. Sci. Total Environ. 408, 1069-1075. 